
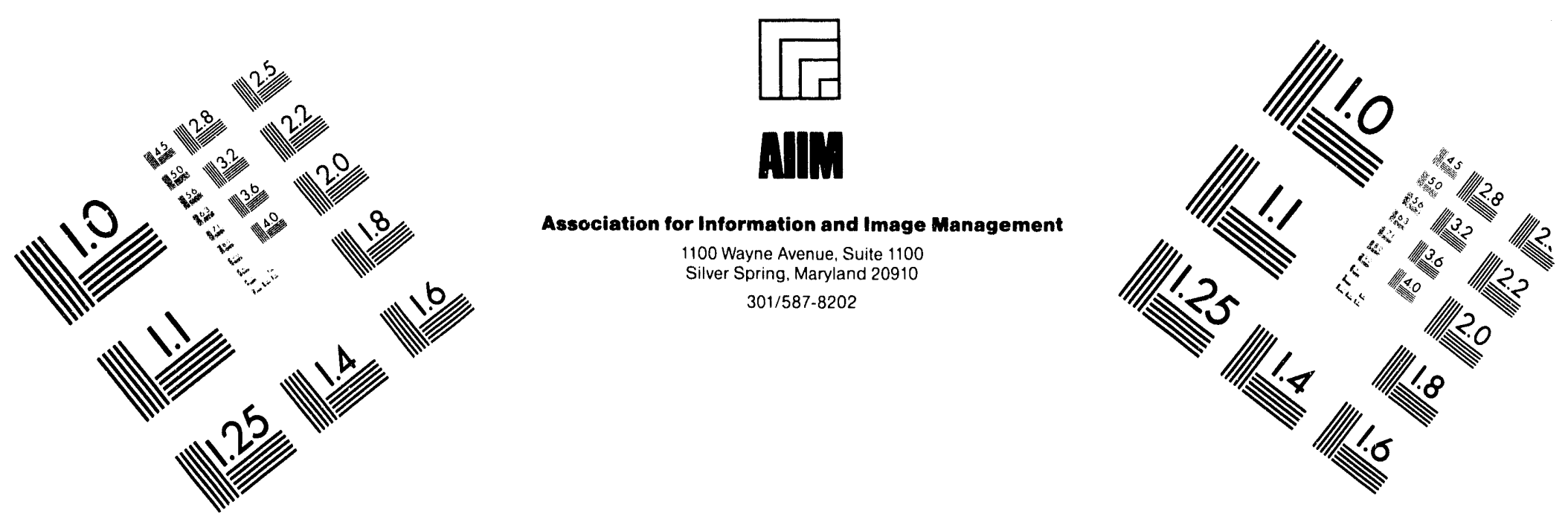

\title{
Centimeter
}

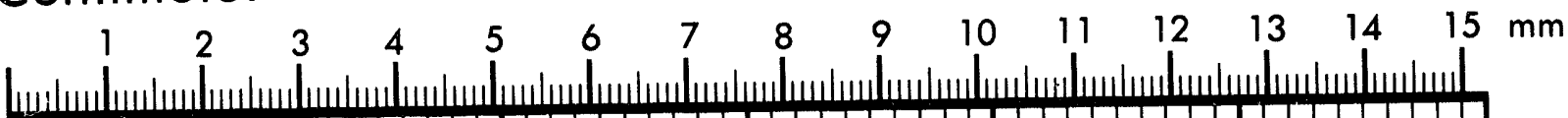

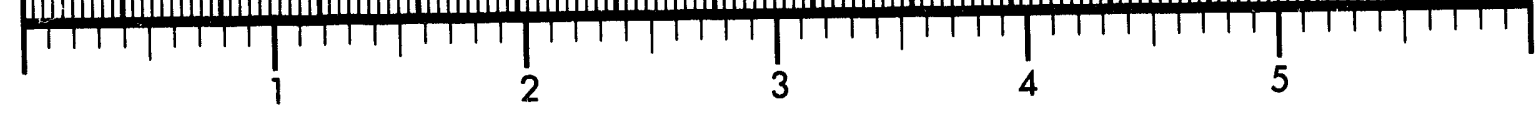
Inches
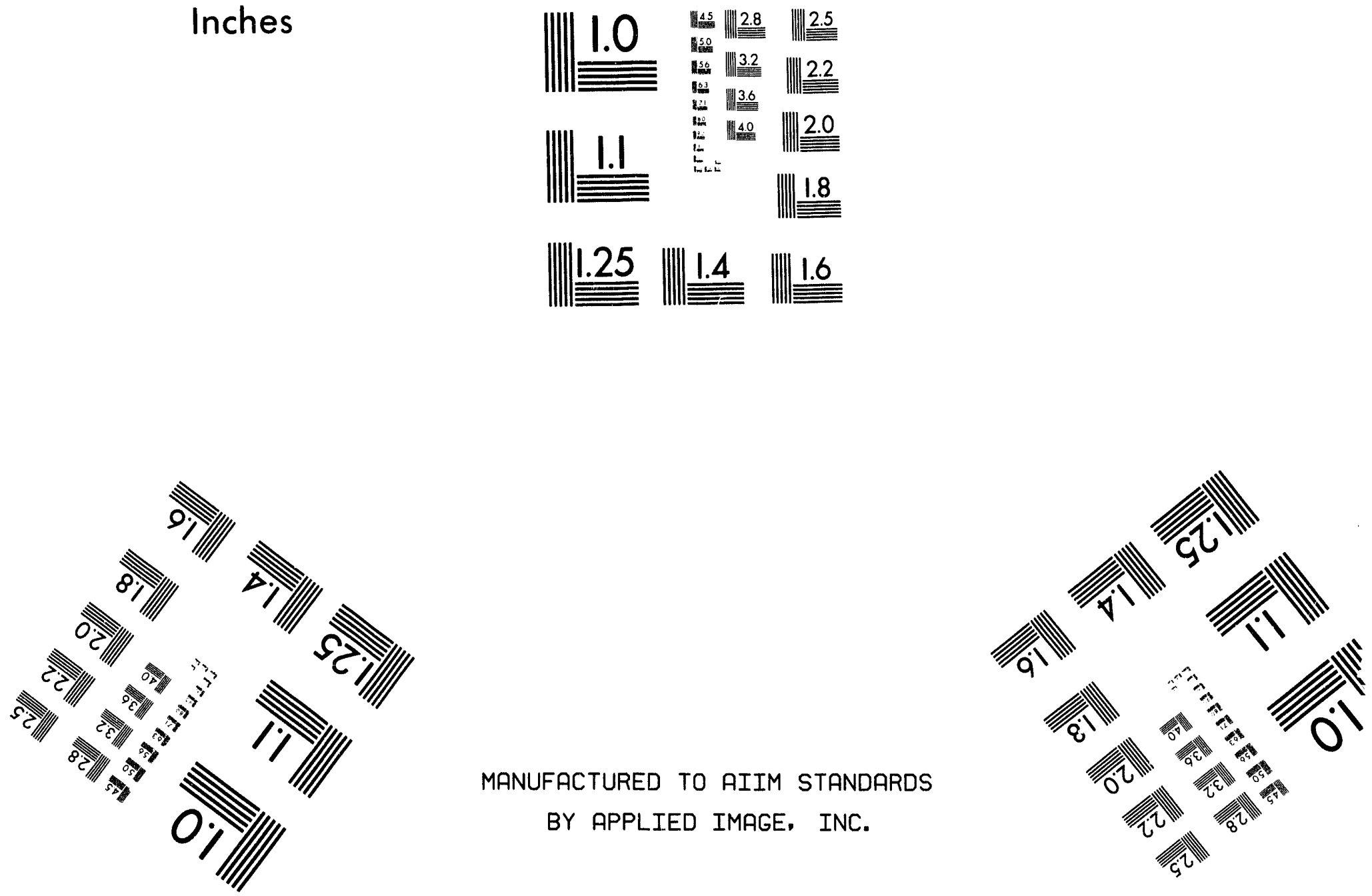

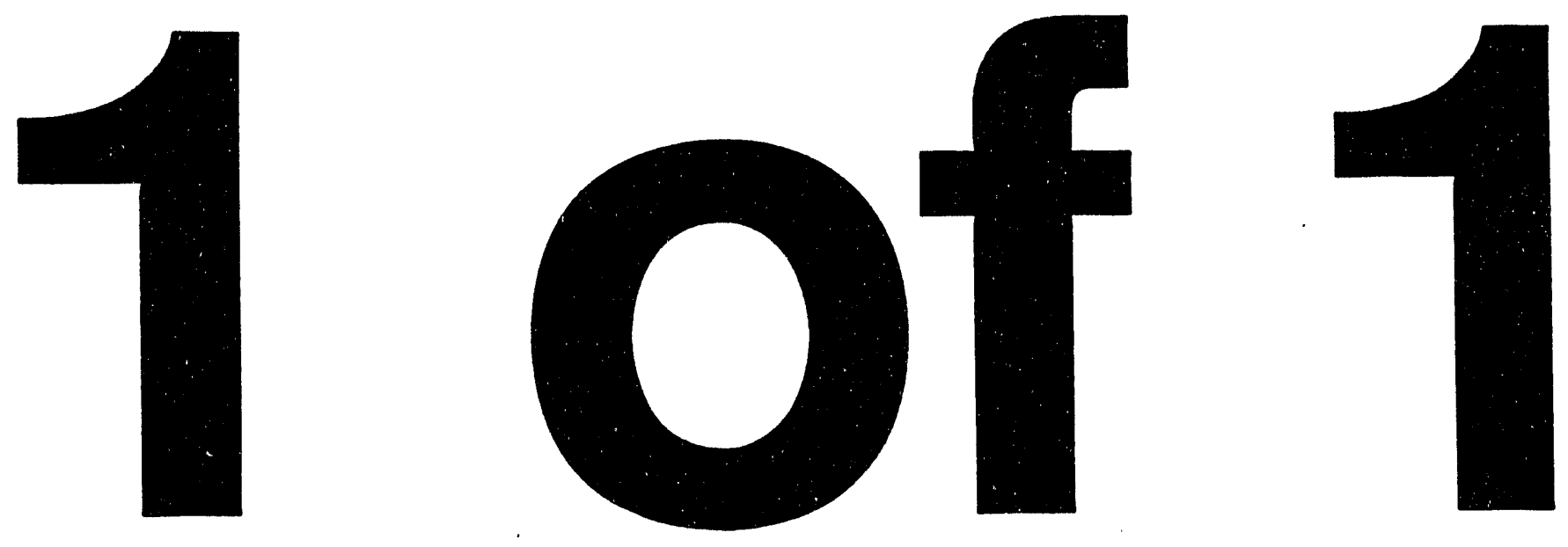


\section{The Superconducting Magnet System for the Tokamak Physics Experiment}

\section{Dwight D. Lang, R.J. Bulmer, M.R. Chaplin, T.G. O'Connor, D.S. Slack,} R.L. Wong, J.P. Zbasnik, J.H. Schultz, N. Diatchenko, D.B. Montgomery, R.D. Pillsbury, Jro, P.W. Wang, L. Myatt, T.G. Brown, J.C. Citrolo

This paper was prepared for submittal to the 11th Topical Meeting on the Technology of Fusion Energy New Orleans, Louisiana

June 19-23, 1994

June 18, 1994

This is a preprint of a paper intended for publication in a journal or proceedings. Since changes may be made before publication, this preprint is made available with the understanding that it will not be cited or reproduced without the permission of the author. 


\section{DISCLAIMER}

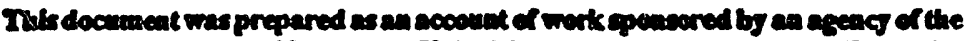

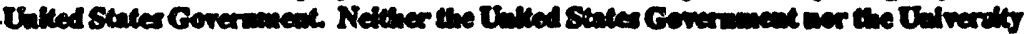

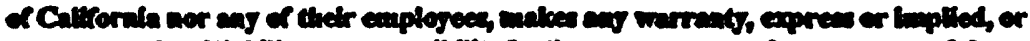

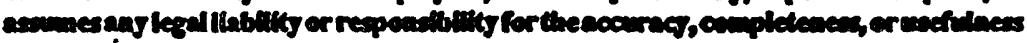

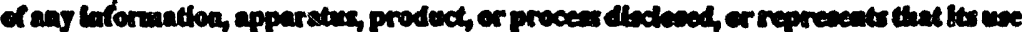

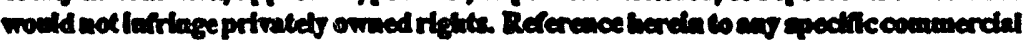

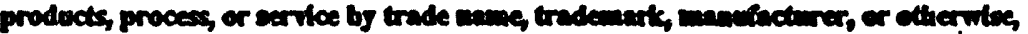

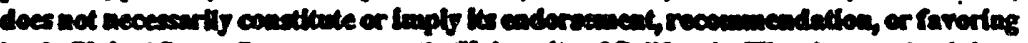

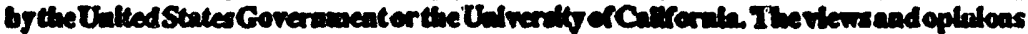

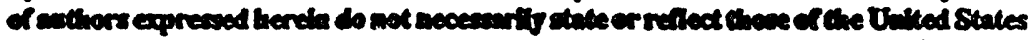

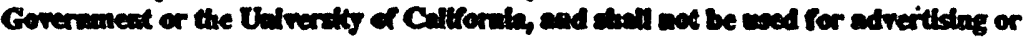
product endorsement purposes. 


\section{THE SUPERCONDUCTING MAGNET SYSTEM FOR THE TOKAMAK PHYSICS EXPERIMENT*}

\author{
Dwight D. Lang, R.J. Bulmer \\ M.R. Chaplin, T.G. O'Connor, \\ D.S. Slack, R. L. Wong \\ J. P. Zbasnik \\ LLNL \\ P.O. Box 808 \\ Livermore, CA 94550
}

\author{
J.H. Schultz, N. Diatchenko, \\ D.B.Montgomery \\ R.D. Pillsbury, Jr., P. W. Wang \\ L. Myatt \\ MIT \\ 185 Albany St. \\ Cambridge, MA 02139
}

\author{
T. G. Brown, J. C. Citrolo, \\ PPPL \\ Princeton University \\ P.O. Box 451 \\ Princeton, N. J. 08543
}

\section{ABSTRACT}

The superconducting magnet system for the Tokamak Physics eXperiment (TPX) will be the first all superconducting magnet system for a Tokamak, where the poloidal field c vils, in addition to the toroidal field coils are superconducting. The magnet system is designed to operate in a steady state mode, and to initiate the plasma discharge ohmically. The toroidal field system provides a peak field of 4.0 Tesla on the plasma axis at a plasma major radius of $2.25 \mathrm{~m}$. The peak field on the niobium 3-tin, cable-in-conduit (CIC) conductor is 8.4 Tesla for the 16 toroidal field coils. The toroidal field coils must absorb approximately $5 \mathrm{~kW}$ due to nuclear heating, eddy currents, and other sources. The poloidal field system provides a total of 18 volt seconds to initiate the plasma and drive a plasma current up to 2 MA. The poloidal field system consists of 14 individual coils which are arranged symmetrically above and below the horizontal mid plane. Four pairs of coils make up the central solenoid, and three pairs of poloidal ring coils complete the system. The poloidal field coils all use a cable-in-conduit conductor, using either niobium 3-tin ( $\mathrm{NB}_{3} \mathrm{Sn}$ ) or niobium titanium (NbTi) superconducting strands depending on the operating conditions for that coil. All of the coils are cooled by flowing supercritical helium, with inlet and outlet connections made on each double pancake.
The superconducting magnet system has gone through a conceptual design review, and is in preliminary design started by the LLNL/MIT/PPPL collaboration. A number of changes have been made in the design since the conceptual design review, and are described in this paper. The majority of the design and all fabrication of the superconducting magnet system will be accomplished by industry, which will shortly be taking over the preliminary design. The magnet system is expected to be completed in early 2000 .

\section{INTRODUCTION}

The Tokamak Physics Experiment (TPX) is a fully superconducting tokamak that will be capable of operating on a steady state basis, while employing many advanced plasma physics techniques including non inductive current drive, high triangularity, and density profile control. The TPX is being designed and built by a national collaboration led by the Princeton Plasma Physics Laboratory[1], with Lawrence Livermore National Laboratory, Oak Ridge National Laboratory, the MIT Plasma Fusion Center, and many other universities and industry. The tokamak will be capable of running double-null, high-beta plasmas, and also single null plasmas. As a major feature of this machine is to run steady state and produce long duration plasmas at full 
operating parameters, a superconducting magnet system was an obvious candidate.

Superconducting magnets have always been seen as an essential feature of any future tokamak based power reactor, but to date only two superconducting tokamaks have been designed and built, and both have had only superconducting toroidal field magnet systems, with resistive poloidal field systems. the Tokamak Physics Experiment will be the first all superconducting tokamak. as the conceptual design described in $[2,3]$. See Table I for a description of the TPX magnet System.

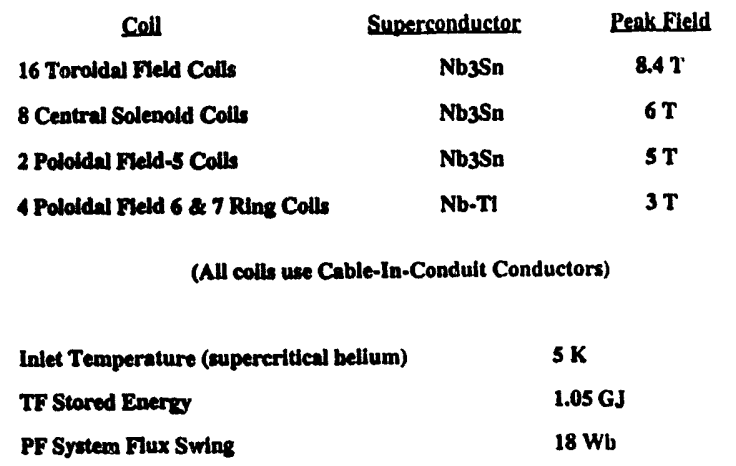

\section{Table I - TPX Magnet System}

The TPX Magnet System must meet the following requirements:

- Satisfy design criteria - fraction of critical current, temperature, margin and head room, power balance, hot spot temperature for protection

- Support magnetic, gravitational, seismic, initiation and disruption loads

- Withstand: 6000 charge-discharge cycles (TF)

- 300 cooldown-warmup cycles (TF \& $\mathrm{PF})$

- 30,000 plasma cycles (TF \& PF)

- Accommodate heat load: $11-\mathrm{kW}$ nuclear 1.4-kW eddy current $300-\mathrm{kJ}$ eddy-current, high-current ramp scenario
The TF System must produce $4.0 \mathrm{~T}$ at a plasma radius of $2.25 \mathrm{~m}$, with field ripple $<0.4 \%$ over plasma volume

Poloidal Field Requirements

- Provide highly shaped double and single null divertor plasma at $2.0 \mathrm{MA}$

- high aspect ratio for long-pulse and steady state

- Provide a $20 \mathrm{~V}$ loop voltage for initiation, which requires a magnetic field ramp rate of $13 \mathrm{~T} / \mathrm{s}$ in the central solenoid

- Provide 18 V-s for initiation and current drive

- Operate at flexibility points at varying confinement and plasma shapes

A key factor in the design of these magnets is the decision to use a manufacturing method[4] where you first wind then react the superconductor, as opposed to the react and then wind method. The $\mathrm{Nb}_{3} \mathrm{Sn}$ superconducting strands only form the $\mathrm{Nb}_{3} \mathrm{Sn}$ alloy during a 3 week reaction heat treatment process, that reaches temperatures of 600-700 degrees $\mathrm{C}$. Once the $\mathrm{Nb}_{3} \mathrm{Sn}$ strand has been reacted, the superconducting filaments are very brittle, and can be broken very easily. Due to this fact, and the previously observed less than optimum performance of react and then wind coils, the wind and then react method was chosen.

Another key decision is to avoid internal joints in individual coils and to use continuous conductors for each of the coils, for the toroidal field coils and for the poloidal coils 1-5. This results in conductors that are $1 \mathrm{~km}$ in length for the TF coils. In order to wind these continuous lengths of conductor, we use a roll forming technique, to form the conductor into pancakes, rather than the more traditional winding (under tension) techniques used for most resistive coils.

\section{CONDUCTORS}

The TF and the PF system both use CIC conductors, with $\mathrm{Nb}_{3} \mathrm{Sn}$ superconducting $0.78 \mathrm{~mm}$ diameter strand being used for the toroidal field coils, and the poloidal 
coils PF1-5 upper and lower (PF1-4 making up the central solenoid). The outer PF ring coils, PF6 and 7, upper and lower, will use NbTi superconducting strand, also with the $0.78 \mathrm{~mm}$ diameter. All conductors are cooled using forced flow supercritical helium. See Table II for a description of the TPX conductors.

\begin{tabular}{|c|c|c|c|c|c|c|c|}
\hline Coll & S/C & $\begin{array}{c}\text { No.S/C } \\
\text { Strands }\end{array}$ & $\begin{array}{l}\text { CusC } \\
\text { Ratio }\end{array}$ & $\begin{array}{l}\text { No. Cu } \\
\text { Strands }\end{array}$ & $\begin{array}{l}\text { Max } \\
\text { Field } \\
T \\
\end{array}$ & $\begin{array}{l}\text { Length } \\
\text { per coll } \\
\text { kmi }\end{array}$ & $\begin{array}{c}\text { Total } \\
\text { S/C } \\
\text { Tonnes } \\
\end{array}$ \\
\hline $\mathrm{TF}$ & Nb3Sn & 486 & 2.5 & 0 & 8.4 & 1.1 & 40 \\
\hline Cs & Nb3Sn & 240 & 3.5 & 120 & 6 & $0.3 \cdot 0.6$ & 3.7 \\
\hline PF.5 & Nb3Sa & 240 & 3.5 & 120 & 5 & 1.0 & 1.9 \\
\hline PF-6 & Nb-T] & 240 & 5.0 & 120 & 3 & 2.8 & 5.5 \\
\hline PF-7 & $\mathbf{N b} \cdot \mathrm{Tl}$ & 240. & 5.0 & 120 & 2.6 & 2.3 & 4.4 \\
\hline
\end{tabular}

Total mass of Nb3Sn conductor: 45.6 Tonnes Total mass of Nb-TI conductor: 10 Tonnes

Table II TPX Magnet Superconductors (S/C)

The $\mathrm{Nb}_{3} \mathrm{Sn}$ strand is a high yield, relatively high performance composite with a high critical temperature. The TF strands have a copper to noncopper fraction of 2.5:1. The selection of the number of strands is primarily driven by the peak field of 8.4 $\mathrm{T}$, the peak operating temperature of $6.0 \mathrm{~K}$, and the power balance criteria. The operating current density for the superconducting area is $505 \mathrm{~A} / \mathrm{mm}^{2}$. The copper fraction is primarily driven by optimizing the superconducting performance versus cost, while still providing adequate copper for protection in case of a quench. The critical current of the $\mathrm{Nb}_{3} \mathrm{Sn}$ strand is sensitive to the strain state of the $\mathrm{Nb}_{3} \mathrm{Sn}$ filaments. The expected operating strain is $-0.3 \%$.

The poloidal field $\mathrm{Nb}_{3} \mathrm{Sn}$ strand has a copper to noncopper fraction of 3.5:1, and the $\mathrm{NbTi}$ strand has a copper to noncopper fraction of $5: 1$. In order to save on the cost of the strand ( $\mathrm{NbTi}$ is much cheaper than $\mathrm{Nb}_{3} \mathrm{Sr}$ ), and to save the need for a reaction cycle (not required for $\mathrm{NbTi}$ ), a study was done to see if we could use NbTi in more than just the PF6 \& 7, but the temperature headroom was the limiting criteria that prevented the increased use of $\mathrm{NbTi}$.
The toroidal field conductor (See Figure 1) is made up of 486 of the $\mathrm{Nb}_{3} \mathrm{Sn}$ 2.5:1 strands cabled in a $3 \times 3 \times 3 \times 3 \times 6$ pattern, and the sheathed in a rectangular (aspect ratio of 1.25:1) Incoloy 908 conduit. The rectangular cross-section was chosen to minimize the toroidal width of the TF cases, while causing acceptable growth in the radial or vertical direction. The $\mathrm{Nb}_{3} \mathrm{Sn}$ strands are strain sensitive, and the Incoloy 908 material is chosen for its close match to the thermal contraction characteristics of the $\mathrm{Nb}_{3} \mathrm{Sn}$ strands, while at the same time developing substantial strength through precipitation hardening as part of the reaction process. The conductor is formed into a continuous piece that is $1.06 \mathrm{~km}$ long, by fabricating the strands into a cable with the quench detection sensors. The cabled strands are then placed into the sheath and the sheath formed around the cable to achieve the final size and void fraction. Typical void fraction in the finished conductor, (the ratio of the difference between the volume of the cable and the volume of the inside of the conduit over the volume of the conduit) is $35 \%$. The void space is the space that the supercritical helium flows through to cool the strands and maintain the conductor at superconducting temperatures.

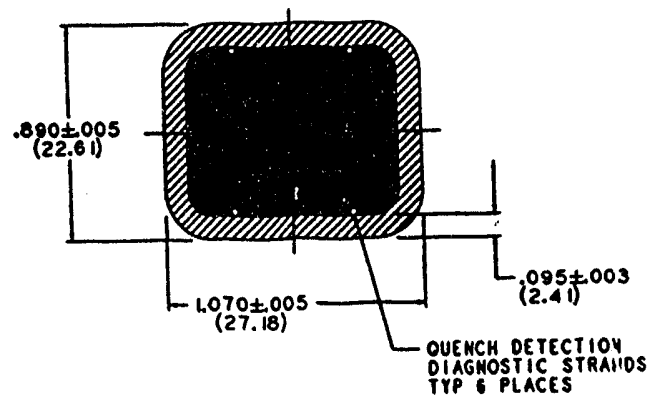

486 Strands of $0.78 \mathrm{~mm}$ Diameter $\mathrm{Nb}_{3} \mathrm{Sn}$ Incoloy 908 Sheath

Figure 1 Toroidal Field Conductor

The PF 1-5 conductors (see Figure 2) use $240 \mathrm{Nb}_{3} \mathrm{Sn}$ superconducting strands and 120 pure copper strands, cabled in a $3 \times 4 \times 5 \times 6$ pattern, and sheathed in a square Incoloy 908 conduit. The pure copper 
strands are used for quench protection, and do not carry any current except when dumping the coils' stored energy because of a quench. The PF 6-7 coils also use 240 superconducting strands, but in this case they are $\mathrm{NbTi}$, along with 120 pure copper strands, and are sheathed in a square, $316 \mathrm{LN}$ stainless steel conduit of the same size as the PF 1-5 conductors. Stainless steel can be used for the conduit with the NbTi strands as they are not strain sensitive. By using the same number of strands in each of the PF coils, and the same size conduit, costs for cable tooling, development and setup time are all minimized.

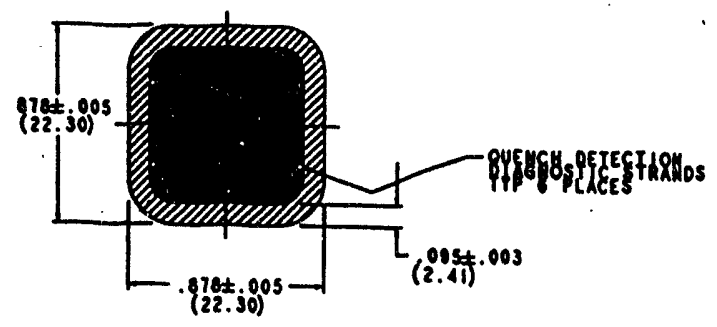

240 Strands of $\mathrm{Nb}_{3} \mathrm{Sn}$ and 120 Strands of Pure Copper Incoloy 908 Sheath

Figure 2 Poloidal Field 1-5 Conductors

\section{TOROIDAL FIELD SYSTEM}

The Toroidal Field (TF) Coil System is made up of sixteen "D" shaped coils contained in a welded case and intercoil support structure, made from $316 \mathrm{LN}$ stainless steel. An individual coil is $4.75 \mathrm{~m}$ high by $3 \mathrm{~m}$ wide. Each of the TF coils is made up of a single continuous length of $\mathrm{CIC}$ conductor, of approximately one $\mathrm{km}$ in length, that is formed into six double pancakes, for a total of 84 turns. (See Figure 3 for a cross-section of the TF winding pack.) The only joints used occur between the coils. The $33.5 \mathrm{kA}$ conductor is based on the US-DPC magnet conductor design and incorporates recent advances in CIC conductois. Thermal analysis [5] is performed both a 1.5 dimension transient thermal hydraulic code with heat inputs due to the nuclear heating, and with eddy current heating (from plasma position control, and from plasma initiation). The transient peak temperature of about $6 \mathrm{~K}$ reaches the sieady state value in about 1500 seconds of operation. At the peak field of $8.4 \mathrm{~T}$ and the maximum temperature of $6.0 \mathrm{~K}$, the TF conductor meets all criteria, with the power balance criteria, $\mathrm{hI}^{2} \mathrm{R} \max =1000 \mathrm{~W} / \mathrm{m}^{2}-\mathrm{K}$ being the most restrictive, with a limit of $6.6 \mathrm{~K}$ at $4.0 \mathrm{~T}$ on axis. Temperature margin required is $1 \mathrm{~K}$, this sets a limit of $6.9 \mathrm{~K}$. Copper fraction is set by optimizing superconductor performance versus cost, while still providing adequate copper to limit hot spot temperature to $150 \mathrm{~K}$ in case of a quench. A copper fraction of 2.5:1 was chosen as having the most robust performance. The coils will be fabricated following a procedure of wind, react, insulate, install in the case, and then vacuum pressure impregnate. The coil will be made using roll benders to form the conductor to the required configuration, using a wind and then back wind technique, allowing the use of the continuous conductor, and avoiding joints. All cross overs, helium connections and electrical connections are made at the top of the coil, minimizing the cross-section of the winding pack in all other locations. After winding, the coils are reacted in a vacuum oven to produce the superconducting niobium 3-tin alloy. The coils are insulated, and are assembled into the case/intercoil structure to form two coil modules (see Figure 4). The eight two coil modules are assembled together to form the complete TF system. The revised TF system including the 486 strand, rectangular conductor and TF structure, have been analyzed, with a 2D finite element model, and all stresses in the metal are acceptable (including quench pressures). A detailed analysis of the winding pack insulation and conductor has shown that the shear and tension stresses in the insulation are higher than currently assumed allowables, primarily at the corners of the conductor. Design changes to the baseline design have been made and analyzed to better understand this problem, and the problem is being worked. A 3D global model of a TF octant, including the PF 5, 6 and 7 coils has been created, 
debugged and will be used to further analyze the TF structure. An analysis of the PF flexibility points shows $38 \%$ higher loads due to the PF coils than the reference high current scenario, the high beta/high $\mathrm{l}_{1}$ point. Stresses increase approximately $4 \%$.

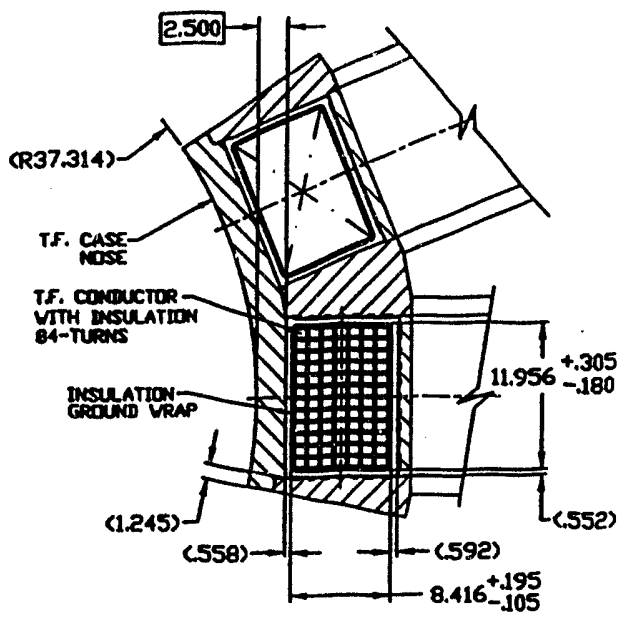

SECTION TAKEN AT INNER HORIZONTAL MIDPLANE

Figure 3 Toroidal Field Coil Winding Pack and Case

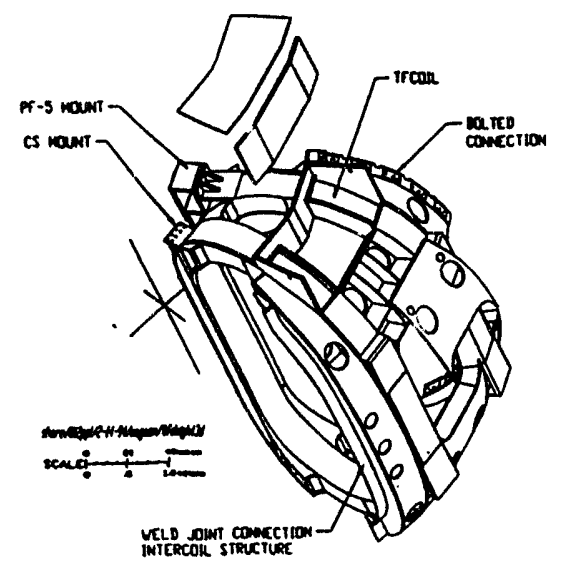

Figure 4 Toroidal Field 2 Coil Module

\section{POLOIDAL FIELD SYSTEM}

The Poloidal Field (PF) Coil System is made up of the central solenoid and 3 pairs of ring coils, with the central solenoid (eight individual coils) and the inner ring coil pair using a niobium 3-tin CIC conductor. These coils will use a similar wind, react, and insulate procedure as is used in the TF coils.
The outer two pairs of ring coils use a niobium titanium superconducting strand, with a $316 \mathrm{LN}$ stainless steel conduit, CIC conductor, and, therefore, will only require a wind and insulate process. Each of the PF coils uses a single continuous piece of conductor wound in a similar way as the TF coils. None of the PF coils will have an external case, but the central solenoid will have a separate compression pre-load structure, ${ }^{[6]}$ hung off the TF structure, that will allow the central solenoid to be installed as an assembly. (See Figure 5.) The outer PF ring coils will be supported off of the TF structure as well. (See Figure 6.) All of the central solenoid connections are made on the inner bore of the coils, to maximize the diameter of the central solenoid by making the central solenoid as close to the TF case as possible.

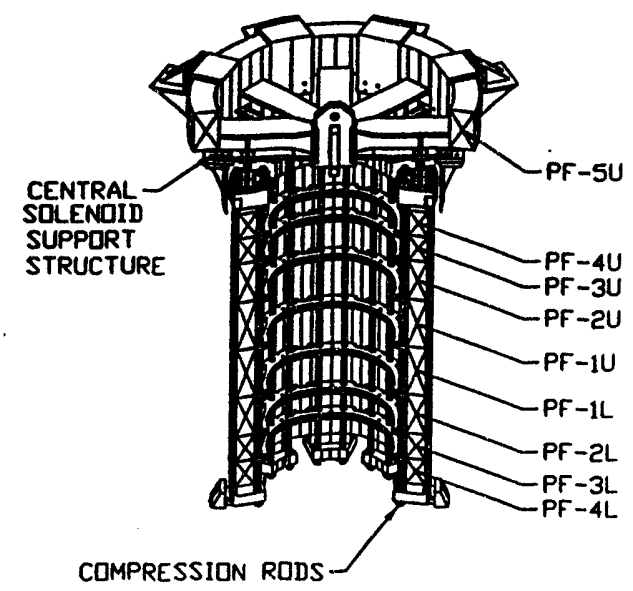

Figure 5 TPX Central Solenoid Assembly

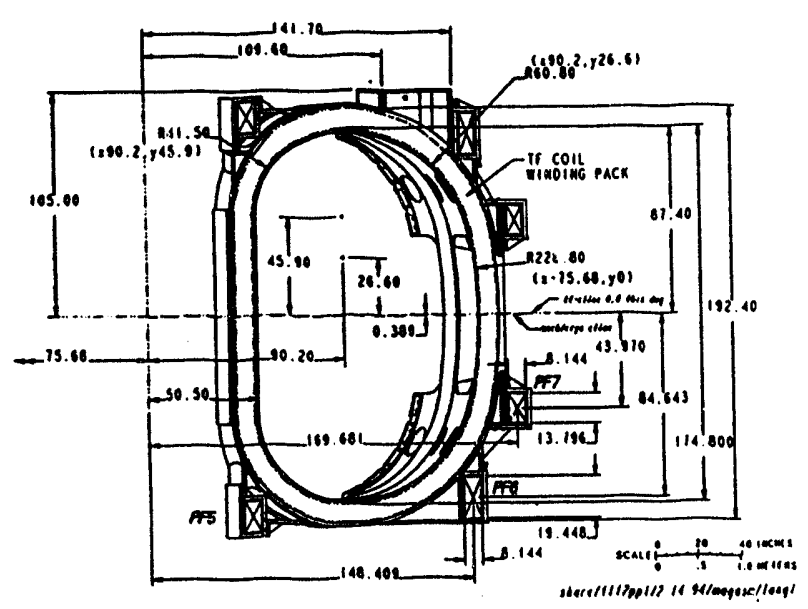

Figure 6 TPX Poloidal Field Ring Coils 
At the CDR the PF system could not operate at all of the corners of flexibility space required for the various advanced physics operating modes. A study was performed to optimize the minimum cost while still meeting the physics flexibility requirements. It was observed that by making the central solenoid coil larger in diameter, the number of turns could be reduced, and by making fewer turns but more pancakes, a lower field on the conductor could be obtained. By making the PF ring coils taller and thinner, the peak field was reduced. The characteristics of the PF coils are given in Table III. The PF coil flexibility study determined a minimum cost PF coil set using the following criteria:fraction of critical current density, power balance, temperature margin, copper current density for quench protection. Plasma initiation studies have shown the PF system required ramp rate is $13 \mathrm{~T} / \mathrm{s}$. High current scenario analysis, with the nuclear heat loads has determined the required number of superconducting strands and the copper fraction of these strands. Quench protection requirements have determined total amount of copper required, and hence the number of pure copper strands. The new PF coil system meets all criteria for fully inductive operation at the high current scenario, and satisfies all physics and engineering constraints, and can operate at all flexibility points.

\begin{tabular}{lcccc} 
& $\begin{array}{c}\text { Central } \\
\text { Solenold } \\
\text { PE 1-4 }\end{array}$ & \multicolumn{3}{c}{ Poloidal Ring Coils } \\
Peak Current, kA & 26 & 26 & 14 & 11 \\
Peak Voltage to ground, kV & 2.8 & 3.8 & 2.9 & 6.5 \\
Peak Field, T & 6.1 & 4.7 & 2.2 & 1.5 \\
Peak Field Ramp Rate, T/sec & 13 & 12.6 & 1.7 & 5.2 \\
Turns per Pancake & 6 & 8 & 6 & 6 \\
Pancakes per coll & 10,16, or 20 & 16 & 20 & 14 \\
Total number of turns & 672 & 256 & 240 & 168
\end{tabular}

Table III Poloidal Field Coils

\section{PROTECTION}

If a quench occurs, it must be detected and the energy in the superconducting coils must be dissipated externally to prevent over heating damage to the coil in the normal zone. The quench detection system[7] is very important as conventional quench detection techniques do not appear to be adequate for the TPX coils due to the plasma induced voltages. Reliable performance of the quench detection system is required due to the large stored energy of the TF system. The PF coil quench detection is expected to be more difficult than the TF due to the rapidly changing and unbalanced voltages. The proposed detection method to be used in both system's sensors include: conventional voltage taps at every double pancake, non inductive co-wound voltage taps, and helium flow sensors on every cooling channel.

The TF coils are electrically connected in series to allow use of a single power supply. The peak voltage of $4 \mathrm{kV}$ to ground ( $8 \mathrm{kV}$ terminal to terminal) occurs in the TF system during a fast discharge of the magnet system, when a quench is detected. The TF stored energy of $1.0 \mathrm{GJ}$ is dissipated by splitting the TF system into two segments, and discharging half of the TF coils into one resistor, and half into another resistor, reducing the peak voltage by a factor of 2. The PF coils are all able to be individually electrically operated, but for double null operation will be connected in symmetrical pairs. The peak voltage of $6.5 \mathrm{kV}$ on the PF coils occurs during the plasma initiation pulse. All of the superconducting magnets will make use of superconducting busses to connect from the magnets to the vapor cooled leads located outside of the TPX experimental vault.

\section{CONCLUSIONS}

The TPX magnet system design has been revised from the conceptual design, and meets all of the operating conditions with the updated heat loads. The preliminary design is underway, and the development ${ }^{[8]}$ of the strand and conductor is in process. 
References:

1. W. Reiersen, "TPX: Tokamak Physics Experiment: Conceptual Design Overview," TPX No. 91-930319-PPPL/Reiersen-02

2. W.V. Hassenzahl, et al, "Superconducting Magnet System for the TPX Tokamak," IEEE Magnet Technology Conference, MT13, Victoria, Sept 1993

3. J.H. Schultz, et al, The TPX Superconducting Magnet System", 15th Symposium on Fusion Energy, Oct. 11, 1993

4. J.C. Citrolo, et al, "TPX Superconducting Magnet Fabrication Process", 15th Sym. on Fusion Energy, Oct. 11, 1993

5. R.L. Wong, et al "Thermo-Hydraulic Analysis of the TPX Superconducting TF Magnets" 15th Sym. on Fusion Energy, Oct. 11, 1993

6. T.G. O'Connor, et al, "Structural Design PF Coils for TPX", 15th Sym. on Fusion Energy, Oct. 11, 1993

7. M.R. Chaplin, et al, "Quench Detection \& Instr. for TPX Magnets", 15th Sym. on Fusion Energy, Oct. 11, 1993

8. J.P. Zbasnik et al, "TPX Magnet R\&D Program" 15th Sym. on Fusion Energy, Oct. 11, 1993

*This work was performed under the auspices of the U.S. DOE by LLNL under contract no. W-7405-Eng-48. 

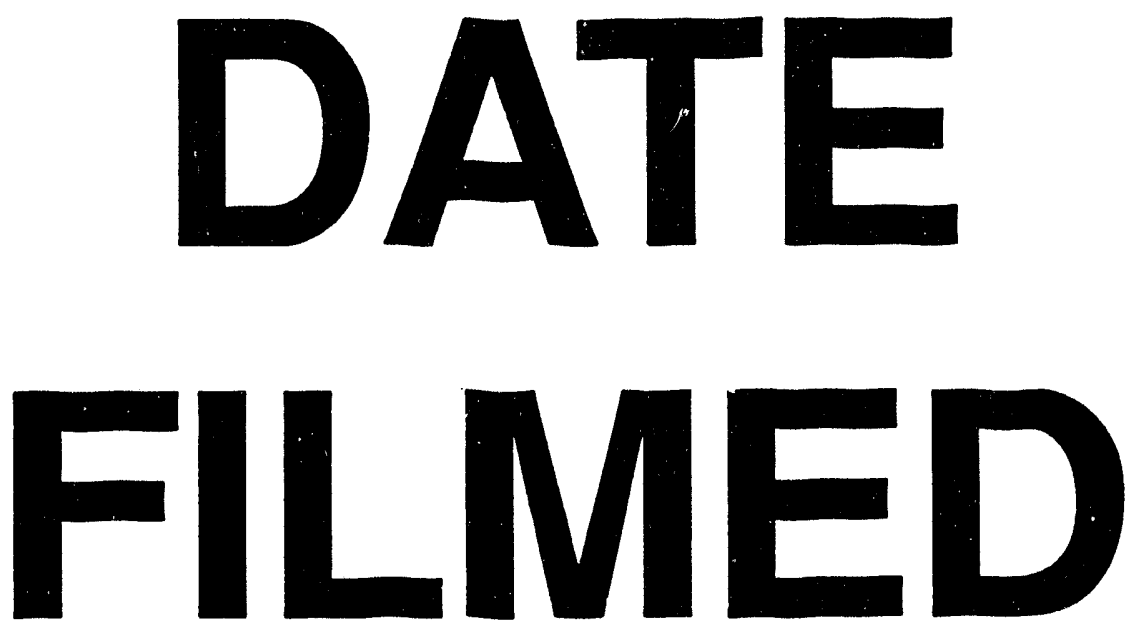

$10 / 17 / 94$
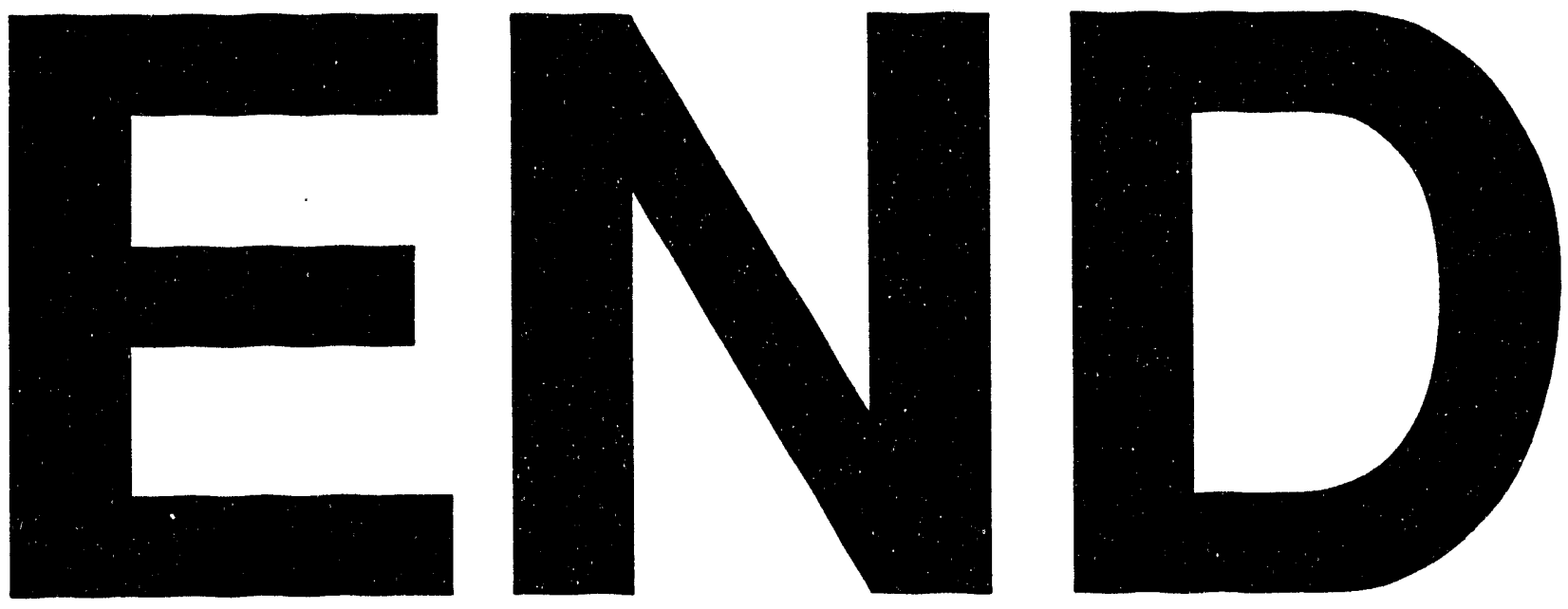
